\title{
A Postscript on Issues, Dating, Reviews, Readers, Prices, and Prizes
}

\section{Issues and Their Dating}

This double issue rounds out thirteen years of The Iowa Review. More accurately, it closes out the fourteen and a quarter years it has taken us to produce thirteen volumes. This tardiness results from our gradual redefinition of an issue, and its solution is mostly a matter of cataloging.

Our printing contract has always specified four issues annually of 96-128 pages. An average issue would run to 112 pages, an average volume to about 450 . Through Volume Ten (1979) we held closely to that norm while falling about a half year behind. But Volume Eleven (1980) contained 656 pages and Volume Twelve (1981) 772, as we began to include novellas, a play, more special features, and came out also with a large Women's Issue. Volume Thirteen continues this pattern. It contains 624 pages, making the last three volumes the equivalent-at least in pages-of almost four and a half volumes by our original way of planning.

Consequently we have decided to consider ourselves caught up. Our next issue will be marked 14/1,1984, which will be the year of its appearance. No separate volume will be dated 1983, that year having been distributed silently through the larger issues we have been publishing. We have put "1983," in parenthesis, on the cover of this issue in order to indicate the time of the greater part of its preparation.

Nor will we return to those slender issues of around 100 pages. We find the 160-200 page format far more convenient. It allows for occasional long contributions, for features on single topics or writers, and for more reviewing of books. We find also we work best with three publications annually, a rhythm our recent double issues have allowed us to discover. Therefore Volume Fourteen and subsequent volumes will contain three issues, each in the neighborhood of 176 pages. Fourteen will actually be larger since it will include an International Issue and a Fiction Special, two extended projects that we have been working on for some time. Thereafter we will plan for 500-600 page volumes. 
We find ourselves offering more and more space to reviews, from thirty to fifty pages in recent issues, and plan to continue extensive reviewing except when a special issue makes that inappropriate. The matrix of our attention will be literary culture in the United States, with occasional forays beyond those limits. We hope this increased attention on recent books will appeal to our readers.

The continuum of writer to magazine to book sometimes seems to leave out the reader, without whom the rest would be futile. Occasionally we hear from readers. In one recent issue, a single poem provoked five letters, four of which were surprising in the similarity of their interest. We would like to set aside a few pages in most issues for readers' remarks. Anyone wishing to "write back" to us might indicate that as their purpose. If space presses, we will give priority to subscribers.

Individual subscribers will be happy to know that we plan no increase for them. Our annual rate will remain $\$ 12.00$ for the three-issue 500-600 page volume. But we are going to raise institutional rates to $\$ 20.00$ and the price of single issues to $\$ 5.00$ beginning with Volume Fourteen.

\section{And Prizes}

We take pleasure in congratulating Henri Coulette, Tess Gallagher, Ellen Gilchrist, and Jane Kenyon for work of theirs, from Volume Twelve, that has come out in The Pushcart Prize, VIII. Becky Birtha, Frederick Busch, Carolyn Forché, Ralph Lombreglia, and David Wagoner also received mention from Pushcart, Busch for the first of our Small Press Reviews, a nice way to begin that feature. We would also like to thank American Literary Scholarship: An Annual (1981) for citing our interview with Donald Justice (11/2-3) as the best literary interview of 1980 and for mentioning a second interview in that issue. And, finally, we thank The Christian Science Monitor for naming us one of the five best literary magazines in America in their special section (August 12,1983) on small magazines and presses. We are grateful for the readers we have, for writers who wish to publish with us, and for the good opinion of others when that is forthcoming. Now we'll work toward meriting more of the same as we move into Volumes Fourteen (1984) and Fifteen.

D.H. 